\title{
Application of Taguchi Method in the Optimization of Injection Moulding Parameters for Manufacturing Products from Plastic Blend
}

\author{
S. Kamaruddin, Zahid A. Khan and S. H. Foong
}

\begin{abstract}
This paper presents a study in which an attempt has been made to improve the quality characteristic (shrinkage) of an injection molding product (plastic tray) made from blends plastic (75\% polypropylene (PP) and $25 \%$ low density polyethylene (LDPE)) by optimizing the injection molding parameters using the Taguchi method. The performance of the plastic trays is evaluated in terms of its shrinkage behavior. An orthogonal array (OA), main effect, signal-to-noise $(\mathrm{S} / \mathrm{N})$ ratio and analysis of variance (ANOVA) are employed to analyze the effect of injection molding parameters on the shrinkage behavior of the product. The analysis of the results shows that the optimal combination for low shrinkage are low melting temperature, high injection pressure, low holding pressure, long holding time and long cooling time. Using Taguchi method for design of experiment (DOE), other significant effects such as interaction among injection molding parameters are also investigated.
\end{abstract}

Index Terms-Taguchi method, optimization, injection moulding, low density polyethylene (LDPE), Polypropylene (PP), shrinkage test

\section{INTRODUCTION}

Products made from plastic range from sophisticated products, such as prosthetic hip and knee joints, to disposable food utensils. One of the reasons for enormous popularity of plastics in a wide variety of industrial applications is the tremendous range of properties exhibited by plastics and their ease of processing [1]. Injection moulding is the most important method for manufacturing varieties of plastic components. It is based on the ability of thermoplastic materials to be softened by heat and to harden when cooled [2]. The injection moulding is conceptually simple. In the process of producing plastic tray, the plastic in the form of pellets or granules is melted and then forced into the cavity of a closed mold which gives shape to the plastic. After sufficient time for plastic to solidify (usually by cooling), the

Manuscript received August 19, 2010. This work was supported by the fund from the Short Term Grant Universiti Sains Malaysia.

S. Kamaruddin is with the School of Mechanical Engineering, Engineering Campus Universiti Sains Malaysia, 14300, Nibong Tebal, Pulau Pinang, Malaysia (Phone: 604-5996382; Fax: 604-5941025; e-mail: meshah@eng.usm.my).

Z.A. Khan, is Department of Mechanical Engineering, Faculty of Engineering and Technology, Jamia Millia Islamia, New Delhi - 110025 , INDIA. (E-mail: zahid_jmi@yahoo.com).

S.H. Foong is with the School of Mechanical Engineering, Engineering Campus Universiti Sains Malaysia, 14300, Nibong Tebal, Pulau Pinang, Malaysia. mold is opened and the part is ejected from the mould and the mold is closed again to repeat the cycle [3]. The process parameters such as injection speed, injection pressure, holding pressure, melting temperature, holding time, cooling time and etc. need to be optimized in order to produce finished plastic parts with good quality. Various studies have been carried out to improve or to optimise the quality characteristic so as to produce high quality commercial plastic product on injection moulding machine [4]-[7]. However, most of the researchers did not consider the effect of interaction between parameters on the quality characteristic of the products although, it could be quite significant.

This paper attempts to describe the optimisation of the injection moulding process parameters for optimum shrinkage performance of a plastic tray which is made from polymer blends or polyblends. The concept of physically blending two existing polymers is used to obtain new products or for problem solving as suggested by Jones \& Ellis (1986) [8]. This study has purposely used a blend of $75 \%$ polypropylene (PP) and $25 \%$ low density polyethylene (LDPE) in order to obtain new product that may contribute to make the recycling more economically attractive and to improve the impact strength [9] \& [10]. The study presented in this paper was divided into two stages: In the first stage, the effect of six injection moulding parameters namely injection speed, melting temperature, injection pressure, holding pressure, holding time and cooling time on shrinkage of plastic tray was investigated to obtain significant parameters. In the second stage, effect of five significant parameters namely melting temperature, injection pressure, holding pressure, holding time and cooling time and two interactions: between melting temperature and injection pressure, between injection pressure and holding pressure was explored to determine optimal combination of parameters for low plastic tray shrinkage. In the following, the Taguchi method and method for obtaining optimal combination of parameters are discussed.

\section{THE TAGUCHI APPROACH}

The quality engineering method proposed by Taguchi is commonly known as the Taguchi method or Taguchi approach. His approach provides a new experimental strategy in which a modified and standardized form of design of experiment (DOE) is used. In other words, the Taguchi approach is a form of DOE with special application principles. This technique helps to study effect of many 
factors (variables) on the desired quality characteristic most economically. By studying the effect of individual factors on the results, the best factor combination can be determined [11]. Taguchi designs experiments using specially constructed tables known as "orthogonal array" (OA). The use of these tables makes the design of experiments very easy and consistent [12] and it requires relatively lesser number of experimental trials to study the entire parameter space. As a result, time, cost, and labour saving can be achieved. The experimental results are then transformed into a signal-to-noise $(\mathrm{S} / \mathrm{N})$ ratio. Taguchi recommends the use of the $\mathrm{S} / \mathrm{N}$ ratio to measure the quality characteristics deviating from the desired values. Usually, there are three categories of quality characteristic in the analysis of the $\mathrm{S} / \mathrm{N}$ ratio, i.e. the-lower-the-better, the-higher-the-better, and the nominal-the-better. The $\mathrm{S} / \mathrm{N}$ ratio for each level of process parameters is computed based on the $\mathrm{S} / \mathrm{N}$ analysis. Regardless of the category of the quality characteristic, a greater $\mathrm{S} / \mathrm{N}$ ratio corresponds to better quality characteristics. Therefore, the optimal level of the process parameters is the level with the greatest $\mathrm{S} / \mathrm{N}$ ratio. Furthermore, a statistical analysis of variance (ANOVA) is performed to see which process parameters are statistically significant. With the $\mathrm{S} / \mathrm{N}$ and ANOVA analyses, the optimal combination of the process parameters can be predicted. Finally, a confirmation experiment is conducted to verify the optimal process parameters obtained from the parameter design.

\section{Optimization of Plastic InJection Moulding PARAMETERS WITHOUT CONSIDERING THE INTERACTION EFFECT}

\section{A. Selection of the injection moulding parameters and their levels}

Plastic injection moulding experiments were carried out on a Battenfeld TM750/210 machine. The feasible space for the moulding parameters was defined by varying the injection speed in the range $80-90 \mathrm{rpm}(\%)$, the melting temperature in the range $220-240{ }^{\circ} \mathrm{C}$, the injection pressure in the range 100-120 bar, the holding pressure in the range $80-96$ bar, the holding time in the range $5-10 \mathrm{sec}$ and the cooling time in the range $5-10 \mathrm{sec}$. Most of these ranges were selected in light of the data available in the literature, machine technical data, and plastics injection moulding handbooks. Two levels of the first parameter and three levels each of the other five parameters were selected as shown in Table 1.

TABLE 1: INJECTION MOULDING PARAMETERS AND THEIR LEVELS

TABLE 1: INJECTION MOULDING PARAMETERS AND THEIR LEVELS
\begin{tabular}{|c|l|c|c|c|c|}
\hline Factor & \multicolumn{1}{|c|}{ Parameter } & Unit & Level 1 & Level 2 & Level 3 \\
\hline A & Injection Speed & rpm (\%) & 80 & 90 & - \\
\hline B & Melting Temperature & ${ }^{\circ} \mathrm{C}$ & 220 & 230 & 240 \\
\hline C & Injection Pressure & bar & 100 & 110 & 120 \\
\hline D & Holding Pressure & bar & 80 & 88 & 96 \\
\hline E & Holding Time & sec. & 5 & 8 & 10 \\
\hline F & Cooling Time & sec. & 5 & 8 & 10 \\
\hline
\end{tabular}

\section{B. Selection of Orthogonal array}

The selection of an appropriate orthogonal array (OA) depends on the total degrees of freedom of the parameters. Degrees of freedom are defined as the number of comparisons between process parameters that need to be made to determine which level is better and specifically how much better it is. In this study, since each parameter has three levels except injection speed which has two levels the total degrees of freedom (DOF) for the parameters are equal to 11 . Basically, the degrees of freedom for the OA should be greater than or at least equal to those for the process parameters. Therefore, an $L_{18}\left(2^{1} \times 3^{7}\right)$ orthogonal array with eight columns and eighteen rows was appropriate and used in this study. The experimental layout for the injection moulding parameters using the $L_{18} \mathrm{OA}$ is shown in Table 2 . Each row of this table represents an experiment with different combination of parameters and their levels. However, the sequence in which these experiments are carried is randomized. The last two columns of the OA are left empty for the error detection of experiments.

TABLE 2: EXPERIMENTAL PLAN USING AN $L_{18}$ ORTHOGONAL ARRAY

\begin{tabular}{|c|c|c|c|c|c|c|c|c|}
\hline \multirow{3}{*}{ Experiment } & \multicolumn{8}{|c|}{ Injection Molding Parameters Level } \\
\hline & $\mathrm{A}$ & $\mathrm{B}$ & $\mathrm{C}$ & $\mathrm{D}$ & $E$ & $\mathrm{~F}$ & $\mathrm{G}$ & $\mathrm{H}$ \\
\hline & $\begin{array}{c}\text { Injection } \\
\text { Speed }\end{array}$ & $\begin{array}{c}\text { Melting } \\
\text { Temperature }\end{array}$ & $\begin{array}{l}\text { Injection } \\
\text { Pressure }\end{array}$ & $\begin{array}{l}\text { Holding } \\
\text { Pressure }\end{array}$ & Holding Time & Cooling Time & - & - \\
\hline 1 & 1 & 1 & 1 & 1 & 1 & 1 & 1 & 1 \\
\hline 2 & 1 & 1 & 2 & 2 & 2 & 2 & 2 & 2 \\
\hline 3 & 1 & 1 & 3 & 3 & 3 & 3 & 3 & 3 \\
\hline 4 & 1 & 2 & 1 & 1 & 2 & 2 & 3 & 3 \\
\hline 5 & 1 & 2 & 2 & 2 & 3 & 3 & 1 & 1 \\
\hline 6 & 1 & 2 & 3 & 3 & 1 & 1 & 2 & 2 \\
\hline 7 & 1 & 3 & 1 & 2 & 1 & 3 & 2 & 3 \\
\hline 8 & 1 & 3 & $\overline{2}$ & 3 & $\overline{2}$ & 1 & 3 & 1 \\
\hline 9 & 1 & 3 & 3 & 1 & 3 & 2 & 1 & 2 \\
\hline 10 & 2 & 1 & 1 & 3 & 3 & 2 & 2 & 1 \\
\hline 11 & 2 & 1 & 2 & 1 & 1 & 3 & 3 & 2 \\
\hline 12 & 2 & 1 & 3 & 2 & 2 & 1 & 3 & 2 \\
\hline 13 & 2 & 2 & 1 & 2 & 3 & 1 & 3 & 2 \\
\hline 14 & 2 & 2 & 2 & 3 & 1 & 2 & 1 & 3 \\
\hline 15 & 2 & 2 & 3 & 1 & 2 & 3 & 2 & $\frac{1}{1}$ \\
\hline 16 & 2 & 3 & 1 & 3 & 2 & 3 & 1 & 2 \\
\hline 17 & 2 & 3 & 2 & 1 & 3 & 1 & 2 & 3 \\
\hline 18 & 2 & 3 & 3 & 2 & 1 & 2 & 3 & 1 \\
\hline
\end{tabular}

\section{Procedure for measuring shrinkage of the plastic tray}

Plastic trays were produced from the plastic blend on the Battenfeld TM750/210 injection moulding machine as per the experimental plan shown in Table 2. Immediately after manufacturing each tray, its original length (dimension in $\mathrm{x}$-direction) and width (dimension in y-direction) were measured with the help of Mitutoyo Linear Height 600 (accuracy $\pm 0.001 \mathrm{~mm}$ ) instrument. Subsequently, these two dimensions were also measured after keeping the tray at an ambient temperature for 24 hours.

The difference between original dimensions and the dimensions after 24 hours indicated the amount of shrinkage that took place in the length and width of the tray. The total shrinkage occurred in the dimension of the tray for each experiment was calculated by adding the length and width shrinkages. The dimensional stability of the plastic trays is related to their shrinkage behavior and that is why shrinkage was considered as a response variable/output characteristic in this study. Less shrinkage means high dimensional stability and vice-versa. It should be noted that the length and width were measured at two extremes and middle of the tray and consequently, three values of shrinkage in length and width were obtained and then average shrinkage was computed. Figure 1 shows the length and width of the tray. 


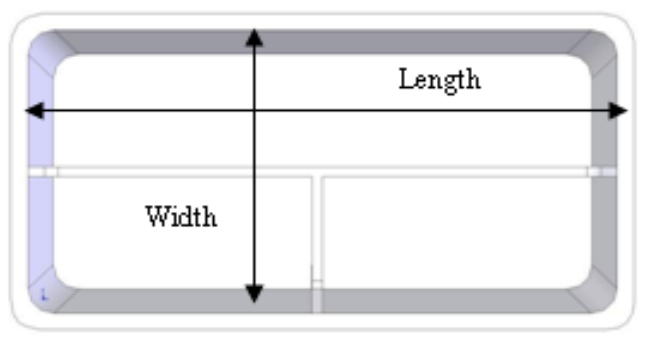

Figure 1: The length and width of the plastic tray

\section{Signal to Noise Ratio $(S / N)$}

The signal to noise ratio $(\mathrm{S} / \mathrm{N}$ ratio) was used to measure the sensitivity of the quality characteristic being investigated in a controlled manner. In Taguchi method, the term 'signal' represents the desirable effect (mean) for the output characteristic and the term 'noise' represents the undesirable effect (signal disturbance, S.D) for the output characteristic which influence the outcome due to external factors namely noise factors. The $\mathrm{S} / \mathrm{N}$ ratio can be defined as [12]:

$$
\mathrm{S} / \mathrm{N} \text { ratio, } \eta=-10 \log (M S D)
$$

where, $M S D$ :mean-square deviation for the output characteristic.

The aim of any experiment is always to determine the highest possible $\mathrm{S} / \mathrm{N}$ ratio for the result. A high value of $\mathrm{S} / \mathrm{N}$ implies that the signal is much higher than the random effects of the noise factors or minimum variance. As mentioned earlier, there are three categories of quality characteristics, i.e. the-lower-the-better, the higher-the-better, and the-nominal-the-better. To obtain optimal moulding performance, the-lower-the-better quality characteristic for shrinkage must be taken. The mean-square deviation (M.S.D.) for the-lower-the-better quality characteristic can be expressed as [12]:

$$
M S D=\frac{1}{n} \sum_{i=1}^{n} y_{i}^{2}
$$

where, $n$ :number of repetitions or observations

$$
y_{i}: \text { the observed data. }
$$

Table 3 shows the experimental results for total shrinkage and the corresponding $\mathrm{S} / \mathrm{N}$ ratio using Eqs. (1) and (2). Since the experimental design is orthogonal, it is then possible to separate out the effect of each parameter at different levels. For example, the mean $\mathrm{S} / \mathrm{N}$ ratio for the melting temperature at levels 1, 2 and 3 can be calculated by averaging the $\mathrm{S} / \mathrm{N}$ ratios for the experiments $1-3$ and 10-12, 4-6 and 13-15, and 7-9 and 16-18, respectively. The mean $\mathrm{S} / \mathrm{N}$ ratio for each level of the other parameters can be computed in the similar manner. The mean $\mathrm{S} / \mathrm{N}$ ratio for each level of the parameters is summarized and called the $\mathrm{S} / \mathrm{N}$ response table for total shrinkage (Table 4).
TABLE 3: EXPERIMENTAL RESULTS FOR TOTAL SHRINKAGE AND S/N RATIO

\begin{tabular}{|c|c|c|c|c|}
\hline \multirow{2}{*}{ Test Drive } & \multicolumn{3}{|c}{ Shrinkage $(\mathrm{cm})$} & S/N Ratio \\
\cline { 2 - 4 } & Width & Length & Total & $(\mathrm{dB})$ \\
\hline 1 & 0.1054 & 0.1752 & 0.2806 & 11.04 \\
\hline 2 & 0.1741 & 0.1813 & 0.3554 & 8.99 \\
\hline 3 & 0.1845 & 0.1961 & 0.3806 & 8.39 \\
\hline 4 & 0.1543 & 0.1800 & 0.3343 & 9.52 \\
\hline 5 & 0.0913 & 0.1801 & 0.2714 & 11.33 \\
\hline 6 & 0.1736 & 0.1603 & 0.3339 & 9.53 \\
\hline 7 & 0.0710 & 0.1534 & 0.2244 & 12.98 \\
\hline 8 & 0.0571 & 0.1822 & 0.2393 & 12.42 \\
\hline 9 & 0.0735 & 0.1637 & 0.2372 & 12.50 \\
\hline 10 & 0.1487 & 0.1874 & 0.3361 & 9.47 \\
\hline 11 & 0.1420 & 0.1360 & 0.2780 & 11.12 \\
\hline 12 & 0.1761 & 0.1498 & 0.3259 & 9.74 \\
\hline 13 & 0.2226 & 0.1629 & 0.3855 & 8.28 \\
\hline 14 & 0.0966 & 0.1960 & 0.2926 & 10.67 \\
\hline 15 & 0.0899 & 0.1483 & 0.2382 & 12.46 \\
\hline 16 & 0.0575 & 0.1588 & 0.2163 & 13.30 \\
\hline 17 & 0.0836 & 0.1617 & 0.2453 & 12.21 \\
\hline 18 & 0.1538 & 0.1099 & 0.2637 & 11.58 \\
\hline
\end{tabular}

TABLE 4: THE S/N RESPONSE TABLE

\begin{tabular}{|c|l|c|c|c|}
\hline \multirow{2}{*}{ Symbol } & \multirow{2}{*}{ Parameter / Factors } & \multicolumn{3}{|c|}{ Mean S/N ratio (dB) } \\
\cline { 3 - 5 } & & Level 1 & Level 2 & Level 3 \\
\hline A & Injection Speed & 10.74 & 10.98 & - \\
\hline B & Melting Temperature & 9.79 & 10.30 & 12.50 \\
\hline C & Injection Pressure & 10.76 & 11.12 & 10.70 \\
\hline D & Holding Pressure & 11.47 & 10.48 & 10.63 \\
\hline E & Holding Time & 11.15 & 11.07 & 10.36 \\
\hline F & Cooling Time & 10.54 & 10.45 & 11.60 \\
\hline
\end{tabular}

Figure 2 shows the $\mathrm{S} / \mathrm{N}$ response graph for total shrinkage. As shown in Eqs. (1) and (2), the greater is the $\mathrm{S} / \mathrm{N}$ ratio, the smaller is the variance of total shrinkage around the desired (the-lower-the-better) value. However, the relative importance amongst the parameters for total shrinkage still needs to be known so that optimal combinations of the parameter levels can be determined more accurately. This will be discussed in the next section using the analysis of variance.

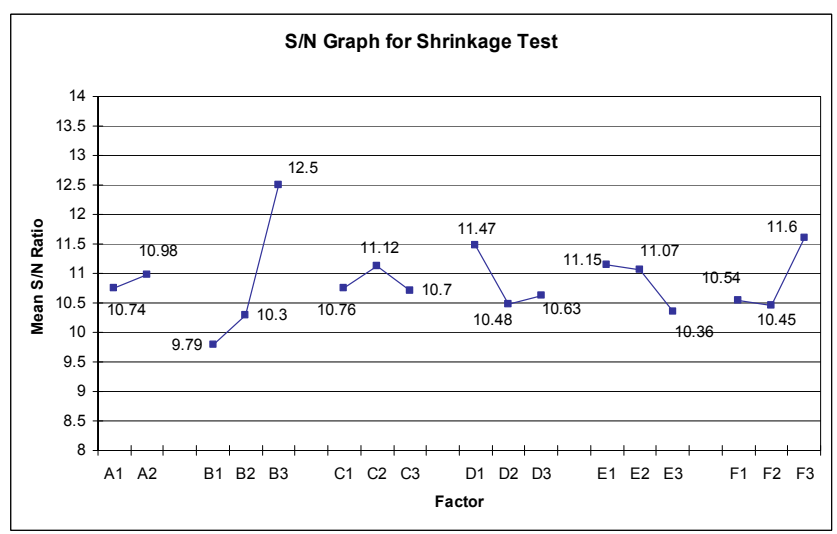

Figure 2: $\mathrm{S} / \mathrm{N}$ response graph 


\section{E. Analysis of Variance (ANOVA)}

The purpose of the analysis of variance (ANOVA) was to find which parameters significantly affected the quality characteristic. The total sum of square deviation, $S S_{T}$ can be calculated using [12]:

$$
S S_{T}=\sum_{i=1}^{n} y_{i}^{2}-C . F .
$$

where, $n$ is the number of experiments in the orthogonal array, $y_{i}$ is the total shrinkage of $i$ th experiment and C.F. is the correction factor. C.F was calculated as [12]:

$$
C . F .=\frac{T^{2}}{n}
$$

where, $T$ is the sum of all total shrinkage.

The total sum of square deviations, $S S_{T}$ was decomposed into two sources: the sum of squared deviation, $S S_{d}$ due to each process parameter and the sum of square error, $S S_{e}$. The percentage contribution, $P$ by each of the process parameter in the total sum of square deviation, $S S_{T}$ was a ratio of the sum of square deviation, $S S_{d}$ due to each process parameter to the total sum of square deviation, $S S_{T}$.

Statistically, there is a test called $F$-ratios (variance ratio) to see which parameters have significant effects on the quality characteristic of plastic tray. For performing the $F$ test, the mean of square deviation, $S S_{m}$ due to each process parameter needs to be calculated. The mean of square variations, $S S_{m}$ is equal to the sum of square deviation, $S S_{d}$ divided by the number of degree of freedom associated with the process parameters. Then, the $F$ value for each process parameter is simply the ratio of the mean of square deviation, $S S_{m}$ to the mean of square error, $S S_{e}$

Table 5 shows the results of pooled ANOVA for the shrinkage test. The F-ratios were obtained for $95 \%$ level of confidence. In addition, percentage contribution of each parameter was also calculated. The melting temperature was the most significant factors that contributed maximum to the total shrinkage of the tray. The contribution from these parameters were melting temperature (52.4\%), holding pressure $(3.6 \%)$, holding time $(0.9 \%)$ and cooling time $(6.9 \%)$. Thus, based on the $\mathrm{S} / \mathrm{N}$ ratio and ANOVA analyses, the optimal combination of parameters and their levels for achieving minimum shrinkage is $\mathrm{A}_{2} \mathrm{~B}_{3} \mathrm{C}_{2} \mathrm{D}_{1} \mathrm{E}_{1} \mathrm{~F}_{3}$ i.e. injection speed at level 2, melting temperature at level 3 , injection pressure at level 2 , holding pressure at level 1, holding time at level 1 , and cooling time at level 3 .

\section{F. Confirmation Test}

The confirmation test is used to verify the estimated result with the experimental results. If the optimal combination of parameters and their levels coincidently match with one of the experiments in the OA, then the confirmatory test is not required. Estimated value of the total shrinkage at optimum condition was calculated by adding the average performance to the contribution of each parameter at the optimum level using the following equations [12]:

$$
\begin{gathered}
\mathrm{Y}_{\mathrm{opt}}=\mathrm{m}+\left(\mathrm{m}_{\text {Aopt }}-\mathrm{m}\right)+\left(\mathrm{m}_{\mathrm{Bopt}}-\mathrm{m}\right)+\left(\mathrm{m}_{\mathrm{Copt}}-\mathrm{m}\right)+\left(\mathrm{m}_{\text {Dopt }}\right. \\
-\mathrm{m})+\left(\mathrm{m}_{\text {Eopt }}-\mathrm{m}\right)+\left(\mathrm{m}_{\mathrm{Fopt}}-\mathrm{m}\right) \\
m=\frac{T}{n}
\end{gathered}
$$

where $\mathrm{m}$ is the average performance, $T$ is the grand total of average total shrinkage for each experiment, $n$ is the total number of experiments and $m_{\text {Aopt }}$ is the average total shrinkage for parameter $\mathrm{A}$ at its optimum level, $m_{\text {Bopt }}$ is the average total shrinkage for parameter B at its optimum level, $m_{\text {Copt }}$ is the average total shrinkage for parameter $\mathrm{C}$ at its optimum level, $m_{\text {Dopt }}$ is the average total shrinkage for parameter D at its optimum level, $m_{\text {Eopt }}$ is the average total shrinkage for parameter $\mathrm{E}$ at its optimum level and $m_{\text {Fopt }}$ is the average total shrinkage for parameter $\mathrm{F}$ at its optimum level.

Confirmation test was required in the present study because the optimum combination of parameters and their levels i.e. $\mathrm{A}_{2} \mathrm{~B}_{3} \mathrm{C}_{2} \mathrm{D}_{1} \mathrm{E}_{1} \mathrm{~F}_{3}$ did not correspond to any experiment of the orthogonal array.

One tray at the optimal combination of parameters and their levels i.e. $\mathrm{A}_{2} \mathrm{~B}_{3} \mathrm{C}_{2} \mathrm{D}_{1} \mathrm{E}_{1} \mathrm{~F}_{3}$ was produced on the same injection moulding machine and from the same material. Shrinkage of the tray was measured in the same way as discussed in section 3.3. The value of total shrinkage obtained from the experiment was compared with the estimated value as shown in Table 6. From Table 6, the

\begin{tabular}{|c|c|c|c|c|c|c|c|}
\hline Symbol & Parameters/ Factors & DOF, $\mathrm{f}$ & $\begin{array}{l}\text { Sum of } \\
\text { Square, } S\end{array}$ & Variance, $V$ & $\begin{array}{c}\text { Variance Ratio, } \\
F\end{array}$ & $\begin{array}{l}\text { Pure Sum } \\
\quad S^{\prime}\end{array}$ & $\begin{array}{c}\text { Percent Contribution } P \\
(\%)\end{array}$ \\
\hline A & Injection Speed & [1] & {$[0.25]$} & \multicolumn{2}{|c|}{ Pooled } & - & - \\
\hline $\mathrm{B}$ & Melting Temperature & 2 & 24.84 & 12.42 & 13.26 & 22.96 & $52.4 \%$ \\
\hline $\mathrm{C}$ & Injection Pressure & [2] & {$[0.62]$} & \multicolumn{2}{|c|}{ Pooled } & & - \\
\hline $\mathrm{D}$ & Holding Pressure & 2 & 3.43 & 1.72 & 1.83 & 1.56 & $3.6 \%$ \\
\hline $\mathrm{E}$ & Holding Time & 2 & 2.27 & 1.13 & 1.21 & 0.40 & $0.9 \%$ \\
\hline $\mathrm{F}$ & Cooling Time & 2 & 4.88 & 2.44 & 2.60 & 3.00 & $6.9 \%$ \\
\hline \multicolumn{2}{|c|}{ All other/ Error } & 9 & 8.43 & 0.94 & & & $36.3 \%$ \\
\hline \multicolumn{2}{|r|}{ Total } & 17 & 43.84 & & & & $100.0 \%$ \\
\hline
\end{tabular}
difference between estimated and experimental result is found to be $0.0239 \mathrm{~cm}$. This shows that the experimental result is strongly correlated with the estimated result

TABLE 5: POOLED ANOVA TABLE FOR TOTAL SHRINKAGE 
TABLE 6: RESULTS OF CONFIRMATION EXPERIMENT

\begin{tabular}{|l|c|c|c|}
\hline \multirow{2}{*}{} & \multicolumn{3}{|c|}{ Optimal Condition } \\
\cline { 2 - 4 } & Estimation & Experiment & Difference \\
\hline \multirow{2}{*}{ Level } & $\mathrm{A}_{2}, \mathrm{~B}_{3}, \mathrm{C}_{2}$, & $\mathrm{A}_{2}, \mathrm{~B}_{3}, \mathrm{C}_{2}, \mathrm{D}_{1}$, & - \\
$\mathrm{D}_{1}, \mathrm{E}_{1}, \mathrm{~F}_{3}$ & $\mathrm{~F}_{3}$ & \\
\hline $\begin{array}{l}\text { Total Shrinkage } \\
(\mathrm{cm})\end{array}$ & 0.1884 & 0.16452 & 0.0239 \\
\hline S/N ratio $(\mathrm{dB})$ & 14.49 & 15.68 & - \\
\hline
\end{tabular}

\section{Optimization of Plastic Injection Moulding} PARAMETERS WITH CONSIDERING THE INTERACTION EFFECT

From the Table 5, it is observed that the injection speed is one of the least significant factors to influence the dimensional stability of the plastic tray. Therefore, only five remaining factors were considered in the design of experiments with interaction. Among these factors, injection pressure was considered to interact with melting temperature and holding pressure. Two levels of each factor were considered. $\mathrm{L}_{8}$ Orthogonal Array was used in this case. Eight plastic trays were produced and their shrinkage was measured as per the details outlined in section 3.3. Table 7 shows the injection moulding parameters and their levels. Table 8 displays the assignment of factors and interactions to the columns of the $\mathrm{OA}$

TABLE 7: INJECTION MOULDING PARAMETERS AND THEIR LEVELS

\begin{tabular}{|c|l|c|c|c|}
\hline Factor & \multicolumn{1}{|c|}{ Parameter } & Unit & Level 1 & Level 2 \\
\hline A & Melting Temperature & ${ }^{\circ} \mathrm{C}$ & 220 & 240 \\
\hline B & Injection Pressure & bar & 100 & 120 \\
\hline C & Holding Pressure & bar & 80 & 96 \\
\hline D & Holding Time & sec. & 5 & 10 \\
\hline E & Cooling Time & sec. & 5 & 10 \\
\hline
\end{tabular}

TABLE 8: EXPERIMENTAL LAYOUT USING AN $L_{8}$ ORTHOGONAL ARRAY

\begin{tabular}{|c|c|c|c|c|c|c|c|}
\hline Test Drive & 兑 & 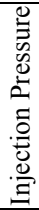 & 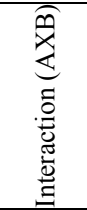 & 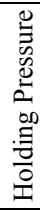 & 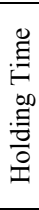 & 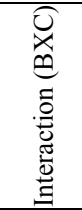 & $\begin{array}{l}\stackrel{\Xi}{\Xi} \\
: 0 \\
: 0 \\
: 0 \\
0 \\
0\end{array}$ \\
\hline & $\mathrm{A}$ & B & $\mathrm{A} \times \mathrm{B}$ & $\mathrm{C}$ & $\mathrm{D}$ & $\mathrm{B} \times \mathrm{C}$ & $\mathrm{E}$ \\
\hline 1 & 1 & 1 & 1 & 1 & 1 & 1 & 1 \\
\hline 2 & 1 & 1 & 1 & 2 & 2 & 2 & 2 \\
\hline 3 & 1 & 2 & 2 & 1 & 1 & 2 & 2 \\
\hline 4 & 1 & 2 & 2 & 2 & 2 & 1 & 1 \\
\hline 5 & 2 & 1 & 2 & 1 & 2 & 1 & 2 \\
\hline 6 & 2 & 1 & 2 & 2 & 1 & 2 & 1 \\
\hline 7 & 2 & 2 & 1 & 1 & 2 & 2 & 1 \\
\hline 8 & 2 & 2 & 1 & 2 & 1 & 1 & 2 \\
\hline
\end{tabular}

Table 9 shows the experimental results for total shrinkage and the corresponding $\mathrm{S} / \mathrm{N}$ ratio using Eqs. (1) and (2) and Table 10 shows the mean $\mathrm{S} / \mathrm{N}$ ratio for each level of the parameters. Figure 3 shows the $\mathrm{S} / \mathrm{N}$ response graph.

TABLE 9: EXPERIMENTAL RESULTS FOR TOTAL SHRINKAGE AND S/N RATIO

\begin{tabular}{|c|c|c|c|c|c|}
\hline \multirow{2}{*}{$\begin{array}{c}\text { Test } \\
\text { Drive }\end{array}$} & \multicolumn{3}{|c|}{ Shrinkage (mm) } & \multirow{2}{*}{$\begin{array}{c}\text { Total } \\
\text { Shrinkage } \\
(\mathrm{cm})\end{array}$} & $\begin{array}{c}\text { S/N Ratio } \\
(\mathrm{dB})\end{array}$ \\
\cline { 2 - 4 } & Width & Length & Total & 0.4336 & 7.26 \\
\hline 1 & 2.1939 & 2.1417 & 4.3357 & 0.2312 & 12.72 \\
\hline 2 & 0.6478 & 1.6642 & 2.3120 & 0 \\
\hline
\end{tabular}

\begin{tabular}{|l|l|l|l|l|l|}
3 & 0.8018 & 1.8694 & 2.6712 & 0.2671 & 11.47 \\
\hline 4 & 0.5306 & 1.3582 & 1.8888 & 0.1889 & 14.48 \\
\hline 5 & 0.2138 & 1.5374 & 1.7512 & 0.1751 & 15.13 \\
\hline 6 & 2.3616 & 2.0802 & 4.4418 & 0.4442 & 7.05 \\
\hline 7 & 0.5786 & 1.5346 & 2.1132 & 0.2113 & 13.50 \\
\hline 8 & 1.3889 & 1.6052 & 2.9942 & 0.2994 & 10.47 \\
\hline
\end{tabular}

TABLE 10: THE S/N RESPONSE TABLE

\begin{tabular}{|c|c|c|c|c|}
\hline Factor & Parameter & Level 1 & Level 2 & Difference \\
\hline A & Melting Temperature & 11.48 & 11.54 & 0.06 \\
\hline B & Injection Pressure & 10.54 & 12.48 & 1.94 \\
\hline A x B & A x B & 10.99 & 12.03 & 1.04 \\
\hline C & Holding Pressure & 11.84 & 11.18 & -0.66 \\
\hline D & Holding Time & 9.06 & 13.96 & 4.90 \\
\hline B x C & B x C & 11.84 & 11.18 & -0.65 \\
\hline E & Cooling Time & 10.57 & 12.45 & 1.88 \\
\hline
\end{tabular}

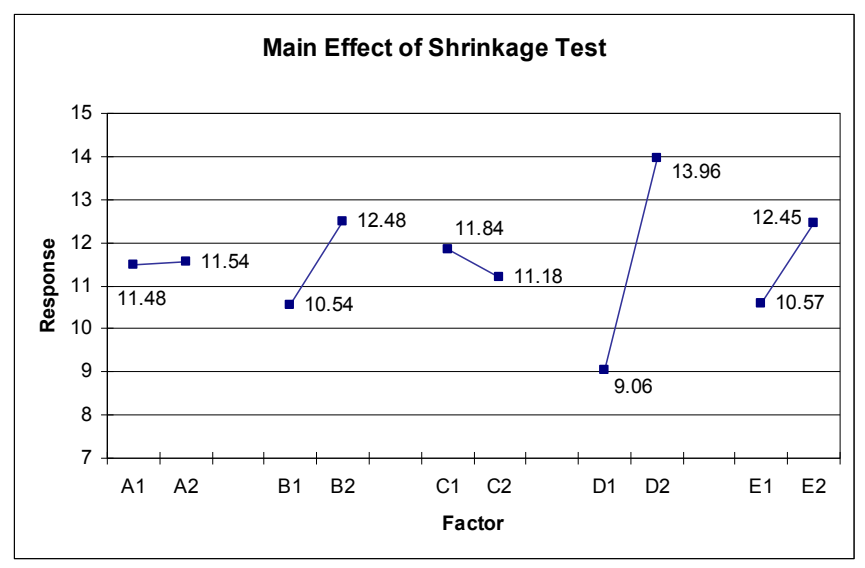

Figure 3: $\mathrm{S} / \mathrm{N}$ response graph

To determine whether the interaction is present, a proper interpretation of the results is necessary. The general approach is to separate the influence of an interacting member from the influences of the others. In this case, A x B and $\mathrm{B} \times \mathrm{C}$ are the interactions with $\mathrm{C}$ common to both.

The value of $A_{1} B_{1}$ is first found from the results that contains both $A_{1}$ and $B_{1}$. It may be noted that the value of $A_{1} B_{1}$ is not the same as the average value at level 1 (Table 10) for interaction $(\mathrm{A} \times \mathrm{B})$ assigned to column 3 in Table 8 . This value is $(\mathrm{A} \times \mathrm{B})_{1}$. In this analysis interaction column, i.e., columns 3 and 6 are not used. Instead columns of Table 8 which represent the individual factors are used. Examination of column 1 shows $A_{1}$ is contained in rows (test drive) 1, 2, 3 and 4 but $\mathrm{B}_{1}$ is in test drive $1,2,5$, and 6 . Comparing the two, the rows that contain both $A_{1}$ and $B_{1}$ are 1 and 2 . Therefore, $\mathrm{A}_{1} \mathrm{~B}_{1}$ comes from the results of test drive 1 and 2 .

The average effect of $\overline{A_{1} B_{1}}=(7.26+12.72) / 2=9.99$. The two common test drives for $\mathrm{A}_{1} \mathrm{~B}_{2}$ are 3 and 4 , and the average effect of $\overline{A_{1} B_{2}}=(11.47+14.48) / 2=12.98$. In the calculations for $\overline{A_{1} B_{1}}$ and $\overline{A_{1} B_{2}}$, factor level $\mathrm{A}_{1}$ is common. The difference between result 9.99 for $\overline{A_{1} B_{1}}$ and 12.98 for $\overline{A_{1} B_{2}}$ is due only to factor B. Similarly, $\overline{A_{2} B_{1}} \overline{A_{2} B_{2}}, \overline{B_{1} C_{1}}, \overline{B_{1} C_{2}}, \overline{B_{2} C_{1}}, \overline{B_{2} C_{2}}$ can 
be calculated. The intersecting line on Figure 4(a) represents the interaction between A and B. The nearly parallel lines on Figure 4(b) show that B and c probably do not interact.

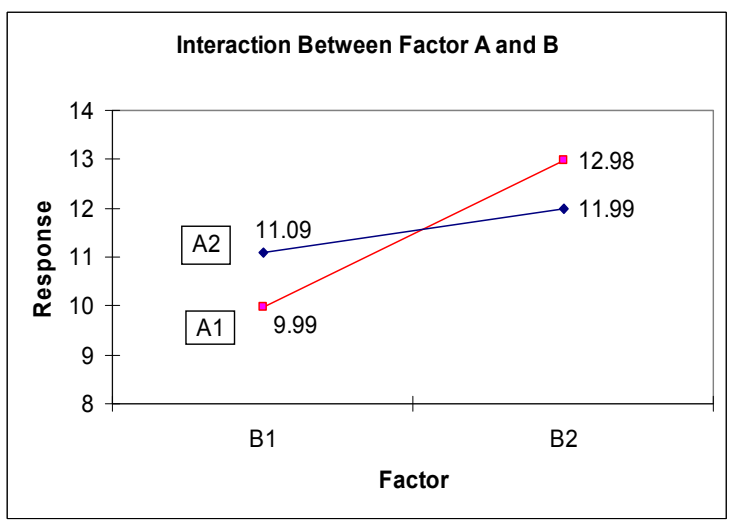

(a)

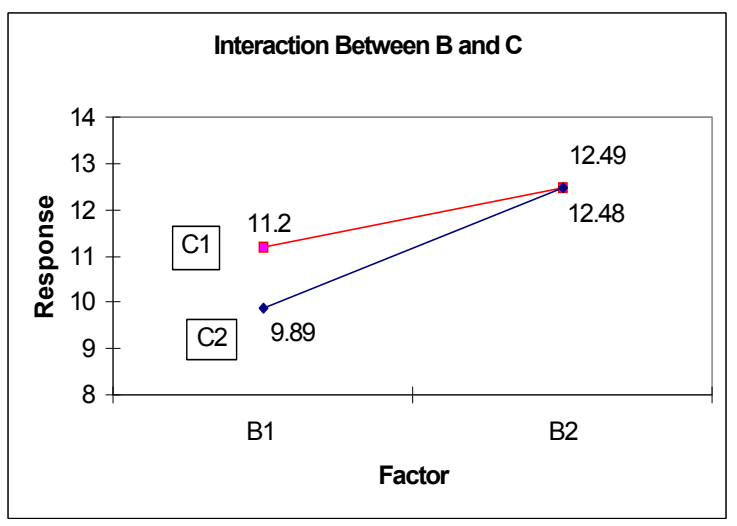

(b)

Figure 4: The test of interaction

\section{A. Analysis of Variance (ANOVA)}

The ANOVA was used to find out the parameters that significantly affected the quality characteristic of the plastic tray. Besides that, the contribution of each parameter was also determined. Table 11 shows the results of pooled

\section{ANOVA.}

F-ratios were obtained for 95\% level of confidence. In addition, percentage contribution of each parameter was also calculated. The injection pressure, holding time and cooling time were the significant factors that contribute to the total shrinkage of the tray. The suspected interaction between factors $\mathrm{B}$ and $\mathrm{C}$ was not found. However, the interaction between $\mathrm{A}$ and $\mathrm{B}$ did exist since its contribution is $2.42 \%$.

The contributions of parameters were injection pressure (10.49\%), holding time (71.45\%) and cooling time (9.77\%). Based on the S/N ratio and ANOVA analyses, the initial optimal combination of parameters and their levels for achieving minimum shrinkage is $A_{2}, B_{2}, C_{1}, D_{2}, E_{2}$ i.e. melting temperature at level 2 , injection pressure at level 2, holding pressure at level 1 , holding time at level 2, and cooling time at level 2.

To re-examine the initial optimum condition, it is suggested to refer figure 4 (a) which shows $A_{1} B_{2}$ has a higher value than $A_{2} B_{2}$. Thus, the optimum condition includes levels $\mathrm{A}_{1}$ and $\mathrm{B}_{2}$. The new optimum conditions become $\mathrm{A}_{1}, \mathrm{~B}_{2}, \mathrm{C}_{1}$, $\mathrm{D}_{2}$ and $\mathrm{E}_{2}$. However, the performance at the new (revised) optimum should be compared with the original (initial) optimum before the final determination of the interaction effect. Consider the initial optimum which excluded the effects of the interaction $\left(A_{2}, B_{2}, C_{1}, D_{2}\right.$ and $\left.E_{2}\right)$.

The estimated shrinkage at this optimum condition was computed following the procedure given in section 3.6 and it was found to be $0.1543 \mathrm{~cm}$. Similarly for the revised optimum, considering interaction, the estimated shrinkage at optimum condition $\left(\mathrm{A}_{1}, \mathrm{~B}_{2}, \mathrm{C}_{1}, \mathrm{D}_{2}\right.$ and $\left.\mathrm{E}_{2}\right)$ was found to be $0.1462 \mathrm{~cm}$.

This shows that the revised optimum yields a smaller value (the-smaller-the-better) of shrinkage, and thus it confirms that the revised optimum is better. It may be noted that when the estimate of the performance at the optimum condition includes the interactions between $\mathrm{A}$ and $\mathrm{B}$, the net result is obtained from the combined effect of $\overline{\mathrm{A}_{1} \mathrm{~B}_{2}}$.

TABLE 11: POOLED ANOVA TABLE

\begin{tabular}{|c|c|c|c|c|c|c|c|}
\hline Factor & Parameter & DOF & $\begin{array}{c}\text { Sum of Square, } \\
\mathrm{S}\end{array}$ & Variance, V & $\begin{array}{c}\text { Variance Ratio, } \\
\text { F }\end{array}$ & $\begin{array}{l}\text { Pure Sum } \\
\quad\left(\mathrm{S}^{\prime}\right)\end{array}$ & $\begin{array}{c}\text { Percent Contribution } \mathrm{P} \\
(\%)\end{array}$ \\
\hline A & Melting Temperature & {$[1]$} & {$[-0.01]$} & \multicolumn{2}{|c|}{ Pooled } & & - \\
\hline $\mathrm{B}$ & Injection Pressure & 1 & 7.50 & 7.50 & 13.56 & 6.95 & $10.49 \%$ \\
\hline $\mathrm{A} \times \mathrm{B}$ & Interaction $\mathrm{A} \times \mathrm{B}$ & 1 & 2.16 & 2.16 & 3.90 & 1.60 & $2.42 \%$ \\
\hline $\mathrm{C}$ & Holding Pressure & {$[1]$} & {$[0.84]$} & \multicolumn{2}{|c|}{ Pooled } & & - \\
\hline $\mathrm{D}$ & Holding Time & 1 & 47.92 & 47.92 & 86.60 & 47.37 & $71.45 \%$ \\
\hline $\mathrm{B} \times \mathrm{C}$ & Interaction $\mathrm{B} \times \mathrm{C}$ & {$[1]$} & {$[0.83]$} & \multicolumn{2}{|c|}{ Pooled } & & - \\
\hline $\mathrm{E}$ & Cooling Time & 1 & 7.03 & 7.03 & 12.71 & 6.48 & $9.77 \%$ \\
\hline & All other/ Error & 3 & 1.660 & 0.55 & & & $5.87 \%$ \\
\hline & Total & 7 & 66.29 & & & & $100 \%$ \\
\hline
\end{tabular}

\section{B. Confirmation Test}

Confirmation test was carried out because the optimum combination of parameters and their levels i.e. $A_{1} B_{2} C_{1} D_{2} E_{2}$ in the present study did not match any experiment of the orthogonal array. The plastic tray at optimal combination of parameters and their levels was produced and its total shrinkage was measured. The estimated value of the total shrinkage at optimum condition was also computed. Table 12 shows a comparison between the estimated value of total shrinkage at optimum condition and the experimental value. A small difference $(0.006 \mathrm{~cm})$ can be observed between these values. This indicates that the experimental value is close to 
the estimated value. Therefore, this verifies that the experimental result is highly correlated with the estimated result.

\begin{tabular}{|l|c|c|c|}
\hline \multirow{2}{*}{\multicolumn{1}{|c|}{ TABLE 12: RESULT OF CONFIRMATION EXPERIMENT }} \\
\cline { 2 - 4 } & \multicolumn{3}{|c|}{ Optimal Condition } \\
\cline { 2 - 4 } & Estimation & Experiment & Difference \\
\hline Level & $\mathrm{A}_{1}, \mathrm{~B}_{2}, \mathrm{C}_{1}, \mathrm{D}_{2}, \mathrm{E}_{2}$ & $\mathrm{~A}_{1}, \mathrm{~B}_{2}, \mathrm{C}_{1}, \mathrm{D}_{2}, \mathrm{E}_{2}$ & - \\
\hline Total Shrinkage $(\mathrm{cm})$ & 0.1462 & 0.1521 & 0.006 \\
\hline S/N ratio & - & 16.35 & - \\
\hline
\end{tabular}

\section{CONCLUSIONS}

From the analysis of the results in injection moulding of plastic tray produced from the blend of $75 \%$ polypropylene (PP) and 25\% low density polyethylene (LDPE) using the Taguchi approach, the following can be concluded from the present study:

\section{Optimum parameters without interaction effect:}

- The optimum conditions are $\mathrm{A}_{2}, \mathrm{~B}_{3}, \mathrm{C}_{2}, \mathrm{D}_{1}, \mathrm{E}_{1}, \mathrm{~F}_{3}$ i.e. injection speed (90\%rpm), melting temperature $\left(240^{\circ} \mathrm{C}\right)$, injection pressure $(110$ bar $)$, holding pressure (96 bar), holding time (5 sec), and cooling time $(10 \mathrm{sec})$.

- The optimum total shrinkage is $0.1645 \mathrm{~cm}$

- Melting temperature is the most significant parameter while injection speed is the insignificant parameter.

- The contribution of parameters is melting temperature $(52.4 \%)$, holding pressure $(3.6 \%)$, holding time $(0.9 \%)$ and cooling time $(6.9 \%)$.

Optimum parameters with interaction effect

- The optimum conditions are $\mathrm{A}_{1}, \mathrm{~B}_{2}, \mathrm{C}_{1}, \mathrm{D}_{2}$, and $\mathrm{E}_{2}$ i.e. melting temperature $\left(220^{\circ} \mathrm{C}\right)$, injection pressure $(120$ bar), holding pressure ( $80 \mathrm{bar})$, holding time (10 sec), and cooling time $(10 \mathrm{sec})$.

- The optimum total shrinkage is only $0.1521 \mathrm{~cm}$

- Interaction between melting temperature and injection pressure is higher than the interaction between holding pressure and injection pressure. It implies that lowering the melting temperature and simultaneously increasing the injection pressure will result in smaller shrinkage.

- The suspected interaction between factors injection pressure and holding pressure is not found whereas; the interaction between melting temperature and injection pressure does exist.

- The contributions of parameters are injection pressure $(10.49 \%)$, holding time $(71.45 \%)$ and cooling time $(9.77 \%)$.

\section{ACKNOWLEDGEMENTS}

The authors are grateful acknowledgements with the logistic support from the School of Mechanical Engineering, computer software support from computer lab personnel, $\mathrm{Mr}$. Jamari Sadri and technical support from the injection moulding technician, Mr. Abdul Hamid Fahmi.

\section{REFERENCES}

[1] Harper, C.A., 2000, "Modern Plastic Handbook". Mc Graw Hill Publishers.

[2] Chanda, M. and Roy, S.K., 1998, "Plastic Technology Handbook", $3^{\text {rd }}$ Edition, Revised and Expanded. Marcel Dekker, Inc.

[3] Strong, A.B., 2000, "Plastics: Material and Processing", $2^{\text {nd }}$ Edition, Prentice hall, Inc.

[4] Ozcelik, B. and Erzurumlu, T., 2005, "Comparison of the warpage optimization in the plastic injection molding using ANOVA, neural network model and genetic algorithm". Journal of Material Processing Technology.

[5] Barriere, Th., Liub, B., and Gelin, J.C., 2003, "Determination of the optimal process parameters in metal injection molding from experiments and numerical modeling". Journal of Material Processing Technology, 143-144, pp.636-644.

[6] Tang, S.H., Tan, Y.J., Sapuan, S.M., Sulaiman, S., Ismail, N. and Samin, R., 2007, "The use of Taguchi method in the design of plastic injection mould for reducing warpage". Journal of Material Processing Technology, 182, pp.418-426

[7] Erzurumlu, T. and Ozcelik, B., 2006, "Minimization of warpage and sink index in injection-molded thermoplastic parts using Taguchi optimization method". Journal of Material and Design, 27, pp.853-861.

[8] Jones, D.H.M. and Ellis, J.W., 1986, "Polymer Products: Design, Material and Processing". Chapman and Hall Ltd.

[9] Strapasson, R., Amico, S.C., Pereira, M.F.R. and Sydenstricker, T.H.D., 2005, "Tensile and impact behavior of polypropylene/low density polyethylene blends". Journal of Polymer Testing, 24, pp. 468-473.

[10] Liang, J.Z., Tang, C.Y. and Man, K.C., 1997, "Flow and mechanical properties of polypropylene / low density polyethylene blends". Journal of Material Processing Technology, 66, pp.158-164.

[11] Roy, R.K., 2001, "Design of Experiments using The Taguchi Approach: 16 Steps to Product and Process Improvement". John Wiley \& Sons, Inc.

[12] Roy, R.K., 1990, "A Primer on the Taguchi method". Competitive Manufacturing Series, Van Nostrand Reinhold, New York.

Shahrul Kamaruddin received the B.Eng.(Hons) degree from University of Strathclyde, Glasgow, Scotland in 1996, the M.Sc. degree from University of Birmingham, U.K., in 1998, and the PhD from University of Birmingham, in 2003. Currently an Associate Professor at the School Mechanical Engineering (under the manufacturing engineering with management programme), Universiti Sains Malaysia. He has various past experiences with manufacturing industries from heavy to electronics industries especially in the field of industrial engineering, manufacturing processes and product design. He has more than 20 publications in reputed international and national journals/conferences. His current research interests include simulation and modeling of manufacturing systems, production planning and control, maintenance management and application of artificial intelligence techniques in manufacturing

Zahid A. Khan received the B.Sc. degree in Mechanical Engineering and the M.Sc. degree in Industrial and Production Engineering from Aligarh Muslim University, Aligarh, India, in 1986 and 1989, respectively, and the Ph.D. degree from Jamia Millia Islamia (A Central University), New Delhi, India, in 2001 in Mechanical Engineering.He is associated with the Department of Mechanical Engineering, Faculty of Engineering and Technology, Jamia Millia Islamia, New Delhi, India, since 1990. He has supervised many undergraduate and postgraduate projects. He has more than 20 publications in reputed international and national journals and more than 30 in international and national conferences and is the coauthor of three books. His current research interests include design and process optimization, Application of soft computing techniques, study of the effects of environmental parameters such as Noise, Vibration, and Illumination etc. on humans. He is on the panel of reviewers for Biosystems Engineering.

S.H. Foong received the Bachelors Degree in Manufacturing Engineering with Management from the Universiti Sains Malaysia. 